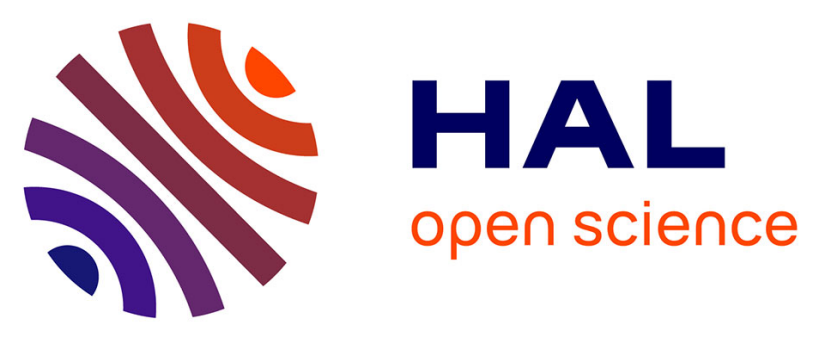

\title{
Successive bilingualism and executive functions: The effect of second language use on inhibitory control in a behavioural Stroop Colour Word task
}

Karin Heidlmayr, Sylvain Moutier, Barbara Hemforth, Cyril Courtin, Robert Tanzmeister, Frédéric Isel

\section{To cite this version:}

Karin Heidlmayr, Sylvain Moutier, Barbara Hemforth, Cyril Courtin, Robert Tanzmeister, et al.. Successive bilingualism and executive functions: The effect of second language use on inhibitory control in a behavioural Stroop Colour Word task. Bilingualism: Language and Cognition, 2014, 17 (03), pp.630-645. 10.1017/S1366728913000539 . hal-01100697

\section{HAL Id: hal-01100697 https://hal.science/hal-01100697}

Submitted on 8 Jan 2015

HAL is a multi-disciplinary open access archive for the deposit and dissemination of scientific research documents, whether they are published or not. The documents may come from teaching and research institutions in France or abroad, or from public or private research centers.
L'archive ouverte pluridisciplinaire HAL, est destinée au dépôt et à la diffusion de documents scientifiques de niveau recherche, publiés ou non, émanant des établissements d'enseignement et de recherche français ou étrangers, des laboratoires publics ou privés. 


\section{Bilingualism: Language and Cognition}

http://journals.cambridge.org/BIL

Additional services for Bilingualism: Language and Cognition:

Email alerts: $\underline{\text { Click here }}$

Subscriptions: $\underline{\text { Click here }}$

Commercial reprints: $\underline{\text { Click here }}$

Terms of use : $\underline{\text { Click here }}$

\section{Successive bilingualism and executive functions: The effect of second language use on inhibitory control in a behavioural Stroop Colour Word task}

KARIN HEIDLMAYR, SYLVAIN MOUTIER, BARBARA HEMFORTH, CYRIL COURTIN†, ROBERT TANZMEISTER and FRÉDÉRIC ISEL

Bilingualism: Language and Cognition / FirstView Article / January 2014, pp 1 - 16

DOI: 10.1017/S1366728913000539, Published online: 29 November 2013

Link to this article: http://journals.cambridge.org/abstract S1366728913000539

How to cite this article:

KARIN HEIDLMAYR, SYLVAIN MOUTIER, BARBARA HEMFORTH, CYRIL COURTIN†, ROBERT TANZMEISTER and FRÉDÉRIC ISEL Successive bilingualism and executive functions: The effect of second language use on inhibitory control in a behavioural Stroop Colour Word task. Bilingualism: Language and Cognition, Available on CJO 2013 doi:10.1017/ S1366728913000539

Request Permissions : $\underline{\text { Click here }}$ 


\section{Successive bilingualism and executive functions: The effect of second language use on inhibitory control in a behavioural Stroop Colour Word task*}

\author{
KARIN HEIDLMAYR \\ Institute of Psychology, Sorbonne Paris Cité - Paris \\ Descartes University, France \& Institute for Romance \\ Studies, University of Vienna, Austria \\ S YLVAIN MOUTIER \\ Developmental and Neurofunctional Imaging Group - \\ GINDEV UMR 6232, CNRS, Sorbonne Paris Cité- \\ Paris Descartes University, France \\ BARBARA HEMFORTH \\ Laboratoire de Linguistique Formelle, UMR 7110 , \\ CNRS, Paris Diderot University, France \& Laboratoire \\ d'Excellence EFL, Sorbonne Paris Cité, France \\ CYRIL COURTIN ${ }^{\dagger}$ \\ Developmental and Neurofunctional Imaging Group - \\ GINDEV UMR 6232, CNRS, Sorbonne Paris Cité- \\ Paris Descartes University, France \\ ROBERT TANZMEISTER \\ Institute for Romance Studies, University of Vienna, \\ Austria \\ FRÉ DÉ R I C IS E L \\ Institute of Psychology, Sorbonne Paris Cité - Paris \\ Descartes University, France \& Laboratoire \\ d'Excellence EFL, Sorbonne Paris Cité, France
}

(Received: August 29, 2012; final revision received: August 29, 2013; accepted: August 29, 2013)

Here we examined the role of bilingualism on cognitive inhibition using the Stroop Colour Word task. Our hypothesis was that the frequency of use of a second language (L2) in the daily life of successive bilingual individuals impacts the efficiency of their inhibitory control mechanism. Thirty-three highly proficient successive French-German bilinguals, living either in a French or in a German linguistic environment, performed a Stroop task on both French and German words. Moreover, 31 French monolingual individuals were also tested with French words. We showed that the bilingual advantage was (i) reinforced by the use of a third language, and (ii) modulated by the duration of immersion in a second language environment. This suggests that top-down inhibitory control is most involved at the beginning of immersion. Taken together, the present findings lend support to the psycholinguistic models of bilingual language processing that postulate that top-down active inhibition is involved in language control.

Keywords: executive functions, active inhibition, bilingual language processing, frequency of second language use, Stroop interference

\footnotetext{
* This research was supported by a grant from the University of Vienna awarded to Karin Heidlmayr and by a grant from Paris Descartes University (Projet de Recherches Collaboratives 2010-2011, Paris Descartes University) to Frédéric Isel and has been partially funded by the Labex EFL (ANR/CGI). Earlier reports on this research were presented at the Donostia Workshop on Neurobilingualism (DonostiaSan Sebastian, Spain, September 30 - October 2, 2010) and at the conference Bilingual and Multilingual Interaction (Bangor, UK, March 30 - April 1, 2012). We would like to thank Judith F. Kroll for valuable discussions and for her review, as well as to two anonymous reviewers for their helpful comments on earlier versions of this manuscript. We are also grateful to Karine Doré-Mazars and Lisa Rosenfelt for fruitful comments. We are sad to note that our co-author Cyril Courtin passed away before the publication of the paper.
}

\section{Introduction}

In bilingual and multilingual individuals, the ability to switch between languages and maintain conversations in one target language involves cognitive control processes for reducing lexical (Kroll, Bogulski \& McClain, 2012; Misra, Guo, Bobb \& Kroll, 2012) and grammatical (Kroll, Dussias, Bogulski \& Valdes Kroff, 2012; Tokowicz \& MacWhinney, 2005) interference between languages. Cognitive control is therefore crucial in order to avoid any negative transfer, the incorrect use of an L1 processing strategy in the L2, which would likely impede the process of understanding (Bjorklund \& Harnishfeger, 1995; De Neys \& Van Gelder, 2009; MacWhinney,

Address for correspondence:

Frédéric Isel, PRES Sorbonne Paris Cité, IUPDP, Paris Descartes University, Institute of Psychology, Paris, France

frederic.isel@parisdescartes.fr 
2005; Tokowicz \& MacWhinney, 2005). Executive functions, especially cognitive inhibition, play an essential role in this control process. Like other psychological constructs, such as memory, executive function is multidimensional. Consequently, several models provide different viewpoints of the basic component processes associated with executive functions (for a review, see Godefroy, Jeannerod, Allain \& Le Gall, 2008). Among them, the model of Miyake, Friedman, Emerson, Witzki, Howerter and Wager (2000) postulates a division into the three most discussed executive functions, namely the inhibition of dominant responses ("inhibition"), the shifting of mental sets ("shifting") and the monitoring and updating of information in working memory ("updating"). In this study, we primarily focused on the relation between bilingualism and cognitive inhibition. Different theories of the mind related to cognitive inhibition originated in the 19th century, showing reflex inhibition and central inhibition in the brain. In the wide domain of neuroscience, while various kinds of inhibition can be identified, e.g. lateral inhibition, reciprocal inhibition and recurrent inhibition among others, each kind can be clearly distinguished from another because its mechanism can either be observed neurophysiologically or clearly operationalized in terms of behaviour (Aron, 2007). Unfortunately, this is not the case in psychology. One reason is that cognitive inhibition can only be observed indirectly using experimental paradigms designed to examine many various executive processes. Despite the empirical difficulties to tap these processes, Aron (2007) proposed that there is a major distinction between automatic inhibition (for example, the lateral inhibition between response representations) and active inhibition (the suppression of an irrelevant response). Models of bilingual language processing have postulated that active inhibition occurs in the inhibition of the inappropriate non-target language (Green, 1998). On the basis of this theory, we examined whether the efficiency of active inhibition among bilinguals is influenced by the need to switch language in their daily lives.

Previous studies have shown an improvement of the executive functions based on an increased level of activity in all age ranges. Interestingly, this phenomenon was even observed in age groups that normally exhibit a decreased capacity in their executive functions, i.e. children and older individuals (A. Diamond \& Lee, 2011; Zelazo, Craik \& Booth, 2004; for a review, see Bialystok, 2007). This observation reinforces the idea that executive functions can be trained by different activities, in particular by those requiring attention, memorization, and control of complex processes (A. Diamond, 2011). Playing the biggest role in the increase of executive function is the use of multiple languages (Bialystok, 2006; Bialystok \& DePape, 2009; Costa, Hernández \& Sebastián-Gallés, 2008; J. Diamond, 2010; Kroll, Dussias, Bogulski \& Valdes Kroff, 2012), as well as playing music (Bialystok \& DePape, 2009), playing computer or video games (Bialystok, 2006), or actively performing sports that require high bimanual coordination (A. Diamond \& Lee, 2011; for a review, see A. Diamond, 2011). However, taken together, behavioural studies exploring the advantages yielded by bilingualism on executive functions do not provide a clear picture. While several studies reported a clear advantage for performing various tasks involving inhibitory control (e.g. Bialystok, Craik, Klein \& Viswanathan, 2004; Bialystok, Craik \& Luk, 2008; Costa et al., 2008; Linck, Hoshino \& Kroll, 2008), others did not (Carlson \& Meltzoff, 2008; Morton \& Harper, 2007; for a review, see Costa, Hernández, Costa-Faidella \& Sebastián-Gallés, 2009).

\section{Empirical data on the impact of bilingualism on executive functions}

A series of studies found that bilingual individuals find it easier to solve conflicts occurring in tasks like the Stroop task (Stroop, 1935), the Simon task (Simon \& Ruddell, 1967) or the Tower of Hanoi task. One possible explanation to account for this advantage is that the inhibitory control of bilingual individuals is better trained due to frequent code switching in their daily lives, compared to monolingual individuals (BadzakovaTrajkov, 2008; Bialystok et al., 2004; Bialystok et al., 2008; Costa et al., 2008). In these tasks, a reduced interference effect and/or faster response times are frequently considered to reflect higher capacities of inhibitory control. ${ }^{1}$ Some of these behavioural studies on inhibition controlled for biological age (Bialystok et al., 2008; Bialystok, Craik \& Ryan, 2006; Gathercole, Thomas, Jones, Guasch, Young \& Hughes, 2010) because the efficiency of the executive functions has been shown to vary with age (Best \& Miller, 2010; Bjorklund \& Harnishfeger, 1995; De Neys \& Van Gelder, 2009; A. Diamond, 2006; Treitz, 2006; Zelazo et al., 2004). Using a Stroop task, Badzakova-Trajkov (2008) found reduced Stroop interference for young adult successive ${ }^{2}$ bilinguals with different combinations of L1 and L2 (MacedonianEnglish; German-English), as compared to monolingual young adults (English). Such a bilingual advantage was also observed for older adults (Bialystok et al., 2008) and for children (Gathercole et al., 2010). Furthermore, in young adults, a bilingual advantage was found for the Simon task (Bialystok, 2006; Bialystok \& DePape,

\footnotetext{
1 Some authors have argued that better monitoring capacities in bilinguals compared to monolinguals are reflected by shorter response times and/or reduced interference effects in an ANT task (Costa et al., 2008), in a flanker task (Costa et al., 2009) or in global-local and trail-making tasks (Bialystok, 2010).

2 The term successive bilingualism refers to late bilingualism, which means that the L2 has been acquired after the L1, from the age of seven years on (see Meisel, 2007).
} 
2009), an attentional network task (ANT; Costa et al., 2008), a lateralized attention network task (LANT; Tao, Marzecová, Taft, Asanowicz \& Wodniecka, 2011), and a flanker task (Luk, de Sa \& Bialystok, 2011). A similar bilingual advantage was also reported in older adults with a Simon task (Bialystok et al., 2004; Bialystok et al., 2008; Linck et al., 2008) and in children of different ages with a range of tasks that tested inhibition, e.g. ANT (Yang, Yang \& Lust, 2011), the dimensional card sorting task (Bialystok \& Martin, 2004; for reviews see Bialystok, 2001, 2005), and ToM tasks (Kovács, 2009). Moreover, a bilingual advantage has also been found in switching tasks (Kovács \& Mehler, 2009; Prior \& MacWhinney, 2010), which plausibly include both inhibition and shifting processes (Prior \& MacWhinney, 2010).

Conversely, several studies failed to show that bilingual older adults had an advantage in inhibitory control in a Stroop task (Kousaie \& Phillips, 2012). Furthermore, in children, some studies did not find any advantage resulting from bilingualism, either with a Simon task (Morton \& Harper, 2007) or with an ANT task (Carlson \& Meltzoff, 2008; for a review, see Costa et al., 2009). To sum up, the above-mentioned behavioural studies examining the effect of bilingualism on executive functions do not unequivocally demonstrate an advantage of bilingualism on executive function. Although there is strong evidence to support the claim that multiple language use favours the training of the executive functions, some studies shed doubt on how general this conclusion is. A factor that may account for the diversity of the results may be the varied relative frequency of language use in the different populations of bilingual individuals. Unfortunately, to date, this linguistic factor has not been systematically taken into consideration. Therefore, our goal was to examine the effects of the frequency of language use on the inhibitory control among highly proficient successive French-German bilinguals.

\section{The present study}

The major contribution of the present study was to examine the use of one executive function, inhibitory control in bilingualism, on the performance of an executive task, i.e. the Stroop task. To date there is still no clear-cut picture on the relationship between bilingualism and conflict resolution in executive tasks. Following the hypothesis of A. Diamond and Lee (2011) that all successful programs involved repeated practice and progressively increasing the challenge to the executive functions, we investigated whether the training of task switching in the daily lives of bilingual individuals influenced their performance on the Stroop task. Therefore, in the present study we examined the role of the relative frequency of language use on the inhibitory control. Critically, we investigated the role of the frequency of the daily use of an L2 (German for all participants) on conflict resolution, by testing bilingual participants in two different linguistic environments (either in France, the linguistic environment of their L1, French, or in Germany or Austria, that of the L2, German), while other linguistic factors such as the age of the acquisition (AoA) of the L2 and the proficiency in the L2 were controlled. The rationale was that the regular use of the L2 in the linguistic environment related to this language should increase the activation of the L2. Consequently, we assumed that the L2 has to be inhibited more in the L2 linguistic environment than that of the L1, where this language is not commonly used. Moreover, while successive bilingual individuals in an L1 linguistic environment mostly have to inhibit only one, not highly activated language (i.e. their L2), bilingual individuals living in an L2 linguistic environment often have to inhibit two languages, namely the highly activated automatic L1 (Linck, Kroll \& Sunderman, 2009) and the regularly activated/used L2. Therefore, the more frequent the L2 use, the stronger the inhibitory control due to a regular use of L2. Furthermore, as few studies focused on whether the regular use of an additional third language might reinforce the effects of bilingualism (see J. Diamond, 2010; Chertkow, Whitehead, Phillips, Wolfson, Atherton \& Bergman, 2010), we decided to include in our study the frequency of use of an L3. In order to study the strength of the inhibitory control, a classic Stroop task was administrated to two groups of proficient successive French (L1) - German (L2) bilingual adults.

Using the Colour Word Stroop task (Stroop, 1935) enabled us to study one particular aspect of executive function, inhibitory control, because, in this task, decisions must be based on task-relevant information in the face of distracting information. Indeed, "two conflicting mental representations are active, each associated with a different response, and attention must be paid to only relevant cues" (Bialystok et al., 2006, p. 1342). Specifically, an ink colour must be identified while ignoring the written word itself. Since word reading is more automatic than colour naming, executive control is required to override the tendency to respond on the basis of the word rather than the ink colour. The need of such control is reflected in slower responses when the word name is competing with the ink colour (i.e. incongruent condition like the word green written in red ink) than when it does not (i.e. congruent condition like the word green written in green ink). The conflict in the incongruent condition arises because an automatic process (i.e. word reading) disturbs a controlled process (i.e. print colour naming), the former having to be inhibited to allow the latter to take place. The Stroop effect is calculated by subtracting the mean response times in the congruent condition from those in the incongruent condition. Shorter response times (RT) to 
the incongruent condition, a smaller Stroop effect size, are interpreted to reflect stronger inhibitory control $^{3}$ (Badzakova-Trajkov, 2008; Pardo, Pardo, Janer \& Raichle, 1990). This definition of the Stroop effect is in line with several preceding studies (Bruchmann, Herper, Konrad, Pantev \& Huster, 2010; Coderre, Conklin \& Van Heuven, 2011; Liotti, Woldorff, Perez \& Mayberg, 2000; Naylor, Stanley \& Wicha, 2012; Pardo et al., 1990; Van Veen \& Carter, 2005). The "Inhibition effect" was defined as the RT difference between the incongruent and the neutral conditions (Coderre et al., 2011; the notion "Stroop interference" is also employed in the literature to designate this effect: see Badzakova-Trajkov, Barnett, Waldie \& Kirk, 2009; Qiu, Luo, Wang, Zhang \& Zhang, 2006) and the "Facilitation effect" as the RT difference between the congruent and the neutral condition (Badzakova-Trajkov et al., 2009; Coderre et al., 2011; Hanslmayr, Pastötter, Bäuml, Gruber, Wimber \& Klimesch 2008; MacLeod \& MacDonald, 2000). Thus, the Stroop effect (incongruentcongruent) could be divided into an Inhibition effect (incongruent-neutral) and a Facilitation effect (neutralcongruent).

We expected to replicate the well-known bilingual advantage in the performance of an experimental task involving executive function, i.e. the Stroop task. This effect can be predicted on the basis of both the INHIBITORY Control (IC) model (Green, 1998) and the Bilingual Interactive ACtivation+ (BIA+) model (Dijkstra \& Van Heuven, 2002; Van Heuven, Dijkstra \& Grainger, 1998) in case of conflict resolution. Critically, with respect to the central question of the present study, i.e. the role of the frequency of language use on inhibitory control, we predicted that the size of the Stroop effect should vary as a function of the L2 use frequency, as indicated by the linguistic environment (either L1, France, or L2, Germany). This means that the higher the frequency of the L2 use, the smaller the size of the Stroop effect (better inhibitory control). Moreover, we predicted that Language (L1 vs. L2) has an impact on the degree of interference in the Stroop task. The Stroop effect is predicted to be larger in the L1 than in the L2 due to the higher automaticity and activation of the L1. However, this difference should decrease when the frequency of L2 use increases, as in this environment the L2 becomes more automatic. Thus, we predicted an interaction between frequency of L2 use (e.g. linguistic environment) and Language for the Stroop effect, such that the more the L2 is used, the more automatic it has become, and thus the larger the Stroop effect will be in the L2. We simultaneously predicted a

3 Alternative explanations of control processes involved in the performance of a Stroop task have been proposed; for example, Blais and Bunge (2010) stress that control is exerted on a local stimuluslevel control, and Bugg (2012) claims that multiple levels of cognitive control are implicated in the control processes in a Stroop task. smaller Stroop effect for the L1 in the L2 environment, due to decreased activation of the L1.

\section{Method}

\section{Participants}

Sixty-five right-handed (Edinburgh Handedness Inventory) participants were recruited. Among them, 34 were successive French (L1) - German (L2) bilinguals living either in France $(n=17)$ or in Germany $(n=17)$, and 31 were French monolingual individuals. One bilingual participant was excluded due to missing data for a multiple regression analysis. By their own account, the participants had no history of current or past neurological or psychiatric illnesses; they had normal or correctedto-normal vision and normal colour vision. They were paid $10 €$ per hour for their time. Table 1 displays several linguistic and non-linguistic aspects asked in a questionnaire before the start of the experiment.

\section{Bilingual participants}

Sixteen successive French (L1) - German (L2) bilinguals (12 female) of an average age of $26.8 \pm 3.7$ years were tested in their L1 environment (Paris, France) and seventeen successive French (L1) - German (L2) bilinguals (15 female) of an average age of $32.4 \pm$ 5.2 years were tested in their L2 environment (Hamburg, Germany, or Vienna, Austria). They were all late learners of their L2, German, which they had started to study by the age of 10 at secondary school in France. The mean AoA of German as their L2 was $11.0 \pm 1.2$ years. A criterion for accepting participants for the study was their regular exposure to German during the past three years and at present. Twenty-six out of 33 bilinguals (79\%) reported using an additional L3 whereas only seven out of 33 bilinguals (21\%) reported using an additional L4 on a daily basis.

Each bilingual participant was asked to assess their own proficiency in German on a five-point scale from EXCELLENT PROFICIENCY (1) to POOR PROFICIENCY (5) in the categories Comprehension, Production, READING and Writing. Furthermore, proficiency in German was evaluated with two standardized tests on their proficiency in German as a foreign language, including the DAF test (Das Zertifikat, DAF - Deutsch als Fremdsprache, Einstufungs- und Diagnostiktest). Their evaluated proficiency and objective scores are presented in Table 1. The two groups of bilinguals (L1 environment, L2 environment) differed on the following background measures: Bilinguals in the L2 environment were on average older ( $32.4 \pm 5.2$ years) than bilinguals in the L1 environment $(26.8 \pm 3.7$ years; $p<.001)$. They also reported a higher frequency of L2 use (53.6 \pm $14.7 \%$ vs. $28.7 \pm 17.8 \% ; p<.001)$, a longer duration of 
Table 1. Results from the evaluation of the participants on their language background and on activities such as practising music, doing sports that require high bimanual coordination, and playing

computer/video games. Means and standard deviations (SDs) are indicated for each category.

\begin{tabular}{|c|c|c|c|c|c|c|}
\hline & \multicolumn{2}{|c|}{$\begin{array}{l}\text { Bilinguals - L1 } \\
\text { environment } \\
\quad(n=16)\end{array}$} & \multicolumn{2}{|c|}{$\begin{array}{c}\text { Bilinguals - L2 } \\
\text { environment } \\
\quad(n=17)\end{array}$} & \multicolumn{2}{|c|}{$\begin{array}{l}\text { Monolinguals } \\
\qquad(n=31)\end{array}$} \\
\hline & Mean & $\mathrm{SD}$ & Mean & SD & Mean & SD \\
\hline Age $(\text { years })^{1}$ & 26.8 & 3.7 & 32.4 & 5.2 & 25.2 & 4.1 \\
\hline Frequency of L2 use $(\%)^{2}$ & 28.7 & 17.8 & 53.6 & 14.7 & 0.4 & 0.8 \\
\hline Frequency of L3 use $(\%)^{3}$ & 3.4 & 5.8 & 3.5 & 6.1 & 0.0 & 0.1 \\
\hline Frequency of L4 use (\%) & 0.8 & 2.2 & 0.8 & 1.7 & 0.0 & 0.0 \\
\hline L2 PA ( $1=$ best, $5=$ poor $)$ & 1.7 & 0.5 & 1.4 & 0.5 & - & - \\
\hline L2 PT (\%) & 85.9 & 9.3 & 87.3 & 8.4 & - & - \\
\hline Immersion in L2 environment (years) ${ }^{4}$ & 1.9 & 1.7 & 8.2 & 4.6 & - & - \\
\hline Age of immersion (years) ${ }^{5}$ & 19.1 & 3.7 & 23.8 & 3.5 & - & - \\
\hline Music practice (hr/week) & 0.6 & 1.3 & 0.9 & 1.6 & 0.4 & 0.7 \\
\hline Sport practice $(\mathrm{hr} / \text { week })^{6}$ & 2.7 & 2.2 & 3.8 & 3.8 & 1.7 & 2.1 \\
\hline Video/Computer games (hr/week) & 0.4 & 0.9 & 0.4 & 0.8 & 0.9 & 1.5 \\
\hline
\end{tabular}

L2 PA = Proficiency in German - Autoevaluation; L2 PT = Proficiency in German - Test (DAF - Deutsch als Fremdsprache) $* p<.05, * * p<.01$, $* * * p<.001$

${ }^{1}$ Bilinguals-L2 vs. Bilinguals-L1***, Bilinguals-L2 vs. Monolinguals ${ }^{* * *}$.

${ }^{2}$ All the three pairwise comparisons ${ }^{* * *}$.

${ }^{3}$ Bilinguals-L2 vs. Monolinguals**, Bilinguals-L1 vs. Monolinguals*.

${ }^{4}$ Bilinguals-L1 vs. Bilinguals-L2 ${ }^{* * *}$, Bilinguals-L2 vs. Monolinguals***, Bilinguals-L1 vs. Monolinguals*

${ }^{5}$ Bilinguals-L1 vs. Bilingual-L2***.

${ }^{6}$ Bilingual-L2 vs. Monolinguals*.

immersion in an $\mathrm{L} 2$ environment $(8.2 \pm 4.6$ years vs. $1.9 \pm$ 1.7 years; $p<.001)$, and a higher age of immersion in an L2 environment $(23.8 \pm 3.5$ years vs. $19.1 \pm 1.7$ years; $p<.001)$.

\section{Monolingual participants}

Thirty-one native French speakers (22 females) with an average age of $25.2 \pm 4.1$ years who had had little use of a foreign language during the past three years and at present (see Table 1) were selected.

As shown in previous studies, additional factors such as socio-economic status (Gathercole et al., 2010; Morton \& Harper, 2007), musical practice (Bialystok \& DePape, 2009), video/computer game playing (Bialystok, 2006) or physical activity requiring high coordination (A. Diamond \& Lee, 2011) may influence the performance in a task on inhibitory control. Therefore, these factors were controlled for in the present study and participants of the two language groups did not differ significantly on either of these factors (Table 1).

\section{Stimuli}

An adapted version of the original Stroop task (Stroop, 1935) was used in the experiments. The task was a manual colour response task in which the participants were asked to identify the print colour of the stimuli. Depending on the condition, stimuli were colour words (e.g. "red", "blue", etc.) or non-colour words (e.g. "cat", "dog", etc.). All stimulus words were monomorphemic, monosyllabic words. The three different conditions were congruent, incongruent and neutral. In the congruent condition the meaning of the colour word and the print colour matched, in the incongruent condition the meaning of the colour word and the print colour differed and in the neutral condition, non-colour words were presented in equally varying print colours as in the congruent and incongruent conditions. In L1, French, the following four colour words were presented: ROUGE "red", BLEU "blue", JAUNE "yellow", VERT "green" and in the L2, German, the four corresponding colour words were used: ROT "red", BLAU "blue", GELB "yellow", GRÜN "green". In the neutral condition, four non-colour words were presented in the same four print colours. This control condition was considered as neutral because stimuli did not include colour information, the critical semantic information causing an interference in a Colour Word Stroop task (for a similar use of the neutral condition, see BadzakovaTrajkov et al., 2009; Hanslmayr et al., 2008; MacLeod \& MacDonald, 2000; Qiu et al., 2006). Initial letters 


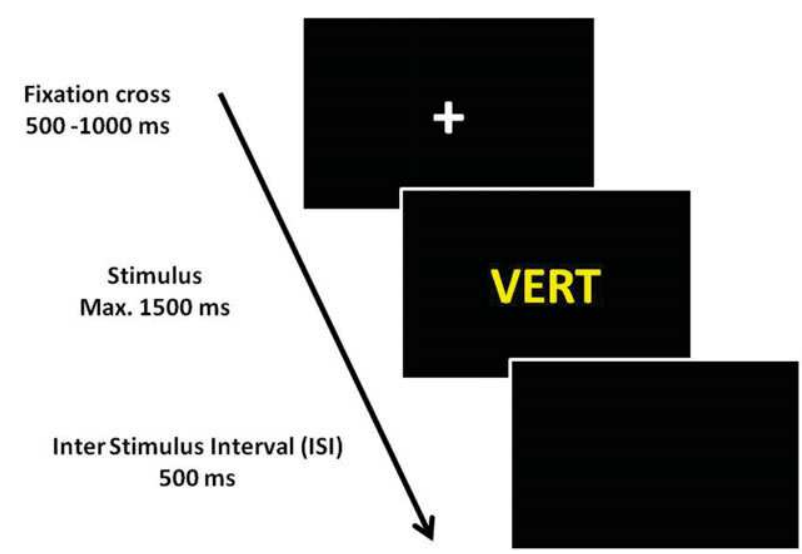

Figure 1. (Colour online) The timing of a trial in the manual version of a Stroop task is displayed.

of colour (congruent and incongruent conditions) and non-colour words (neutral condition) did not share initial letters. CHAT “cat”, CHIEN “dog”, MAIN "hand”, PIED "foot" were chosen as neutral words in L1, French, and their translation equivalents in L2 (German): KATZE "cat", HUND “dog", HAND "hand", FUSS "foot". The stimulus words, written in capitals, in "Calibri" font and in font size 48 , were presented individually against a black background in the centre of the screen.

\section{Procedure}

Some aspects of the stimulus presentation and the experimental procedure were taken from Bruchmann et al. (2010). The stimulus presentation design was created with the program E-Prime 2.0 (Psychological Software Tools, Pittsburgh, PA). Each stimulus word was preceded by a fixation cross in the centre of the screen (Figure 1). The duration of the fixation cross varied between $500 \mathrm{~ms}$ and $1000 \mathrm{~ms}(500,625,750,875,1000 \mathrm{~ms}$ equally distributed and pseudo-randomized among the stimuli) in order to avoid systematic expectancy to be built up by the participants. The fixation cross was immediately followed by the stimulus, which was presented until one of the four colour response keys was pressed or maximally for $1500 \mathrm{~ms}$ if no key was pressed. The inter-stimulus interval (ISI) was $500 \mathrm{~ms}$. Response time (RT) was defined as the interval between the stimulus onset and pressing a response key.

Participants were seated in front of a laptop (Dell, $14^{\prime \prime}$ screen) in a common writing position with both hands positioned on the keyboard. The room contained good lighting conditions. Written instructions were given to the subjects and repeated before running the experiment. The participants were asked to indicate as fast and as correctly as possible the print colour of the stimulus word by pressing one of the four response buttons. The colours were also indicated on the lower part of the screen to facilitate the colour-key-assignment. The keys D, F, J and $\mathrm{K}$ were chosen in order to allow the usual position of the hands on the keyboard. The keys had to be pressed with the index and middle fingers of the left and the right hand. The colour-finger-assignment was counterbalanced between the subjects so as to vary the fingers and the hand used for each colour but kept constant during the experiment for every single participant.

In order to allow the participants to learn the colourkey correspondences, two practice blocks of 40 trials each were presented before the six experimental blocks. For the bilinguals, a block with words in French was presented first, followed by a second block with words in German. For the monolinguals, both practice blocks consisted of words in French. Feedback on the percentage of correct answers was given after each practice and experimental block. If the accuracy was at least $80 \%$ after the second practice block, the experiment was started; if not, the two practice blocks were repeated.

The participants were tested in six blocks each containing 72 trials. In each block, there were 24 congruent stimuli, 24 incongruent stimuli and 24 neutral stimuli, presented in a pseudo-randomized order. A number of constraints were used for the pseudorandomization. First, no more than three words of the same experimental condition were presented in succession. Secondly, no word and no print colour were repeated immediately. Third, the first stimulus of each block was a neutral one. The pseudo-randomized order of trials was created using the program Conan (Nowagk, 1998). Moreover, for each bilingual participant a list was created in which the presentation order of the six blocks (three French and three German) was counterbalanced using the following constraint: No more than two blocks of one language were presented in succession. Monolingual participants saw six blocks in French, but only three of them were used for further analyses in order to match the number of blocks presented to the bilinguals in their L1. The three chosen L1 blocks were those corresponding to the distribution of the L1 block positions for the bilinguals. The participants could take a short pause between the blocks and continue when ready by pressing the spacebar. The experiment lasted about 25 minutes.

Before starting the experiment with the bilingual participants, a conversation in German was held for about 15 minutes between each participant and the experimenter, a German native speaker (the first author of the present study) in order to activate the second language of the participants. Moreover, a language history questionnaire had to be completed. The questionnaire was in German for the bilingual participants, in French for the monolingual participants. Both, the conversations and the questionnaire in German were intended to activate the L2 processing by switching the language processing mode to 
German (see Isel, Baumgaertner, Thrän, Meisel \& Büchel, 2010).

\section{Data analysis}

Response time (RT) was defined as the interval between the onset of the stimulus word and the manual response on the keyboard. Time-out was set at $200 \mathrm{~ms}$ and at $1500 \mathrm{~ms}$; if the participant responded before $200 \mathrm{~ms}$ or after $1500 \mathrm{~ms}$, the response was coded as missing. We averaged the RTs for correct responses in the nine experimental conditions across participants and across items. We excluded RTs \pm two standard deviations from each participant's mean in each experimental condition from the statistical analysis. The average percentage of outliers for bilinguals was $4.44 \pm 1.03 \%$ in L1 and $4.62 \pm 1.19 \%$ in L2, and for monolinguals $4.44 \pm 0.98 \%$.

We subjected the results of errors and response times to a three-way analysis of variance (ANOVA) in which Condition $(\mathrm{C}$; three levels: congruent, incongruent, neutral) and Language (L; two levels: French, German) were considered as within-subjects factors, and Linguistic environment ( $\mathrm{E}$; two levels: bilingual in the L2 linguistic environment, bilingual in the L1 linguistic environment) as a between-subjects factor.

Then, to ensure that we were able to replicate the bilingualism advantage with a Stroop task, a two-way ANOVA in which Condition was considered as a withinsubjects factor and Group (G; two levels: bilingual, monolingual) as a between-subjects factor $(\mathrm{C} 3 \times \mathrm{G} 2)$ was run on errors and RT. To test the effect of Language in the bilingual group, an additional two-way ANOVA in which Condition and Language were considered as within-subjects factors $(\mathrm{C} 3 \times \mathrm{L} 2)$ was calculated. For each ANOVA, Greenhouse-Geisser correction was applied where necessary for sphericity assumption violations and Bonferroni correction was used for post hoc tests.

Finally, two multiple regression analyses were conducted on RT in order to test the role of the frequency of foreign language use and other linguistic factors on the Stroop effect size, which constitutes the central question of the present study.

Five between-subject factors were included to analyse their respective part of variance on the Stroop effect (incongruent-congruent) in L1 and L2: the frequency of L2 use, of L3 use, the L2 proficiency, duration of immersion in an L2 environment, and age of immersion. Frequency of L3 use was considered to be a relevant predictor because 26 out of 33 bilinguals (79\%) reported using an additional L3. In contrast, only 7 out of 33 bilinguals $(21 \%)$ reported using an additional L4 on a daily basis. Thus, frequency of L4 use was not included as a predictor in the multiple regression analysis. A significance level of .05 was used for all statistical tests.

\section{Results}

\section{Analyses of errors}

As neither the main effect Linguistic environment (E; $p>.10)$ nor the interaction between Linguistic environment and Condition and Language were significant $(F<1)$, data of the two groups of linguistic environments were collapsed for further analyses. For bilinguals, the averaged percentage of errors was 2.40 $\pm 2.23 \%$ in $\mathrm{L} 1$ and $2.10 \pm 2.05 \%$ in $\mathrm{L} 2$, and for monolinguals $3.27 \pm 3.11 \%$.

\section{Condition by Language Group interaction (C3 x G2)}

Error rates are displayed for L1 in Table 2. Repeated measures ANOVA $(\mathrm{C} 3 \times \mathrm{G} 2)$ with Condition (three levels: congruent, incongruent, neutral) as a withinsubjects factor and Language Group (two levels: bilingual, monolingual) as a between-subjects factor showed a main effect of Condition $(F 1(2,124)=4.812, \mathrm{MSE}=4.69$, $p<.05)$. This effect was due to significantly increased error rates in the incongruent condition $(3.45 \pm 3.65 \%)$ compared to the congruent condition $(2.33 \pm 2.81 \%$; $F 1(1,62)=10.10, \mathrm{MSE}=8.24, p<.01)$. There was no main effect of Language Group $(p>.10)$ and no significant Condition by Language Group interaction $(p>.10)$.

\section{Condition by Language interaction (C3 x L2)}

Error rates for bilinguals are displayed in Table 3 . The ANOVA failed to show either a main effect of Condition $(p>.10)$, a main effect of Language $(p>.10)$ or a Condition $\times$ Language interaction $(F<1)$.

\section{Analyses of RT}

As neither the main effect Linguistic environment (E) nor the interaction between Linguistic environment and Condition and Language were significant $(F \mathrm{~s}<1)$, data of the two groups of linguistic environments were collapsed for further analyses.

\section{Condition by Language Group interaction (C3 x G2)}

Response time data is displayed for $\mathrm{L} 1$ in Table 2 and Figure 2. The ANOVA showed a significant main effect of Condition $(F 1(2,124)=96.43, \mathrm{MSE}=592.3$, $p<.001)$. This effect reflects that averaged response times were longer in the incongruent condition (678.3 $\pm 97.9 \mathrm{~ms}$ ) than in the (i) congruent condition (625.9 $\pm 91.7 \mathrm{~ms}$; Stroop effect $=52.4 \mathrm{~ms} ; F 1(1,62)=$ 151.91, $\mathrm{MSE}=1168.15, p<.001)-$ mirroring the increased error rates in the incongruent condition (see 
Table 2. Error rates (ERR; \%) and response times $(R T s ; m s)$ in the three experimental conditions (congruent, incongruent and neutral) with the standard deviations (SDs, in parentheses) for the two language groups (bilinguals, monolinguals) in L1 blocks of the Stroop task.

\begin{tabular}{|c|c|c|c|c|}
\hline & & $\begin{array}{c}\text { Bilinguals } \\
(n=33)\end{array}$ & $\begin{array}{l}\text { Monolinguals } \\
\quad(n=31)\end{array}$ & Total \\
\hline & Condition & Mean (SD) & Mean (SD) & Mean (SD) \\
\hline \multirow[t]{3}{*}{ ERR } & Congruent & $2.06(2.57)$ & $2.61(3.05)$ & $2.33(2.81)$ \\
\hline & Incongruent & $2.70(2.84)$ & $4.26(4.25)$ & $3.45(3.65)$ \\
\hline & Neutral & $2.45(3.19)$ & $2.94(3.11)$ & $2.69(3.14)$ \\
\hline \multirow[t]{3}{*}{ RT } & Congruent & $632.5(76.2)$ & $618.9(106.5)$ & $625.9(91.7)$ \\
\hline & Incongruent & $675.7(81.5)$ & $681.0(114.2)$ & $678.3(97.9)$ \\
\hline & Neutral & $652.2(75.0)$ & $638.8(105.4)$ & $645.7(90.5)$ \\
\hline
\end{tabular}

Table 3. Error rates (ERR; \%) and response times (RTs; $m s)$ for $L 1$ and L2 of bilinguals in the three experimental conditions (congruent, incongruent and neutral) with the standard deviations (SDs, in parentheses) for bilinguals in L1 and in L2 blocks of the Stroop task.

\begin{tabular}{|c|c|c|c|c|}
\hline & & L1 French & L2 German & Total \\
\hline & Condition & Mean (SD) & Mean (SD) & Mean (SD) \\
\hline \multirow[t]{3}{*}{ ERR } & Congruent & $2.06(2.57)$ & $1.67(2.26)$ & $1.86(2.14)$ \\
\hline & Incongruent & $2.70(2.84)$ & $2.64(2.61)$ & $2.67(2.34)$ \\
\hline & Neutral & $2.45(3.19)$ & $2.00(2.68)$ & $2.23(2.69)$ \\
\hline \multirow[t]{3}{*}{ RT } & Congruent & $632.5(76.2)$ & $630.3(80.3)$ & $630.9(77.9)$ \\
\hline & Incongruent & $675.7(81.5)$ & $660.2(82.3)$ & $664.1(80.9)$ \\
\hline & Neutral & $652.2(75.0)$ & $641.3(76.6)$ & $644.1(75.1)$ \\
\hline
\end{tabular}

section 3.1.1.) - and (ii) neutral condition $(645.7 \pm 90.5$ $\mathrm{ms}$; Inhibition effect $=32.7 \mathrm{~ms} ; F 1(1,62)=58.11$, MSE $=1189.90, p<.001)$. Moreover, further post-hoc tests showed that averaged response times were shorter in the congruent condition $(625.9 \pm 91.7 \mathrm{~ms})$ compared to the neutral condition $(645.7 \pm 90.5 \mathrm{~ms}$; Facilitation effect $=$ $19.8 \mathrm{~ms} ; F 1(1,62)=54.59$, MSE $=459.05, p<.001)$. Further analyses indicated that the size of the Inhibition effect (incongruent-neutral) did significantly differ from the size of the Facilitation effect $(F 1(1,62)=5.202$, MSE $=1074.53, p<.05)$. In contrast, the main effect of Language Group was not significant $(F<1)$. Moreover, the ANOVA revealed a significant Condition by Language Group interaction $(F 1(2,124)=3.99$, MSE $=592.3$, $p<.05, \eta^{2}=.02$ ), indicating that the effect size between conditions did vary across the two groups of participants (Figure 3). Post-hoc comparisons on the Stroop effect (incongruent-congruent) showed that this interaction was due to a larger Stroop effect in monolingual participants $(62.1 \mathrm{~ms})$ than among bilingual participants $(43.3 \mathrm{~ms}$; $F l(1,62)=4.85$, MSE $=1168.15, p<.05, \eta^{2}=$ $.04)$. The Inhibition effect (incongruent-neutral) mirrored the Stroop effect (incongruent-congruent), as it was significantly larger for the monolingual participants $(42.2 \mathrm{~ms})$ than for the bilingual participants $(23.6 \mathrm{~ms}$; $\left.F 1(1,62)=4.68, \mathrm{MSE}=1189.90, p<.05, \eta^{2}=.04\right)$. In contrast, the size of the Facilitation effect (neutralcongruent) did not differ significantly between the two groups $(F<1)$. In order to examine whether the differences in Stroop and Inhibition effect size between the two language groups are mainly due to RT differences in one of the experimental conditions (congruent, incongruent, neutral), independent samples $t$ tests were done on the RTs in each experimental condition. RTs did not differ between language groups either in the congruent, the incongruent, or the neutral conditions $(t \mathrm{~s}<1)$. This result suggests that group differences in Stroop and Inhibition effects cannot simply be attributed to RT differences in only one of the three experimental conditions (neutral, congruent, incongruent).

\section{Condition by Language interaction (C3 $\times$ L2)}

Response time data for the bilinguals' L1 and L2 are displayed in Table 3 and Figure 4. The Stroop effect (incongruent-congruent) was predicted to be larger in the L1 than in the L2 due to the higher automaticity 


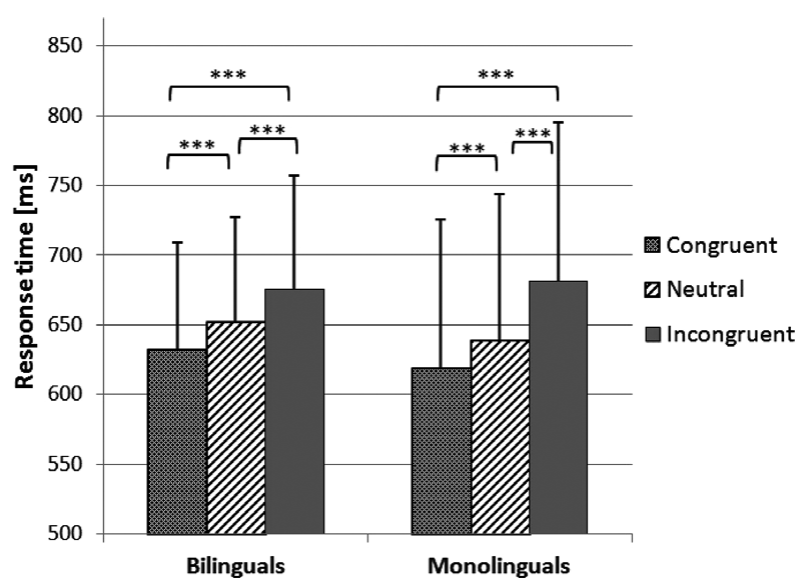

Figure 2. Mean response times (ms) and the standard deviations in the congruent, neutral and incongruent experimental conditions are displayed for bilinguals and for monolinguals in their L1.

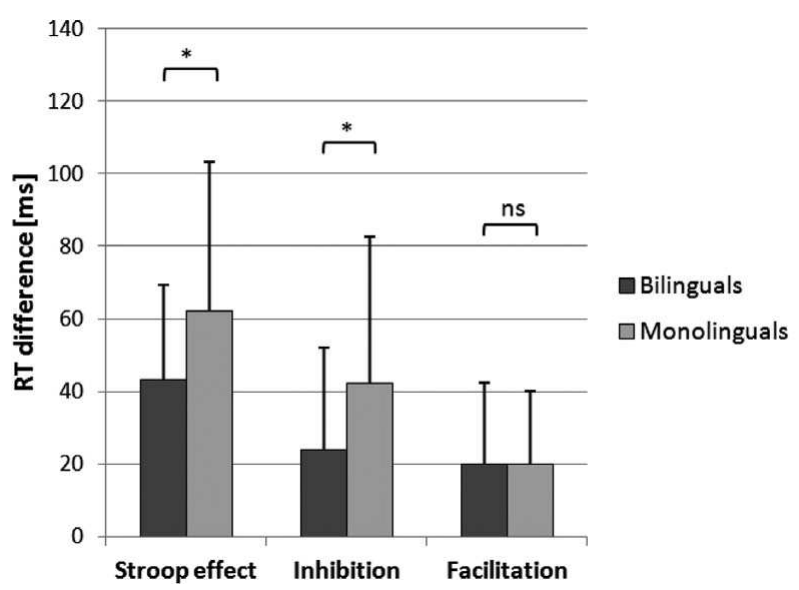

Figure 3. Mean Stroop Effect (ms) $\left(\mathrm{RT}_{\text {incongruent }}-\right.$ $\mathrm{RT}_{\text {congruent }}$; Response time difference between the incongruent and the congruent condition), Inhibition effect $\left(\mathrm{RT}_{\text {incongruent }}-\mathrm{RT}_{\text {neutral }}\right)$ and Facilitation effect $\left(\mathrm{RT}_{\text {neutral }}-\right.$ $\mathrm{RT}_{\text {congruent }}$ ) with their respective standard deviations are given for bilinguals and monolinguals in their L1.

and activation of L1. A two-way repeated measures ANOVA $(\mathrm{C} 3 \times$ L2) with Condition (3 levels: congruent, incongruent, neutral) and Language (2 levels: French, German) as within-subjects factors showed a significant main effect of Condition $(F 1(2,64)=54.90, \mathrm{MSE}=$ 405.33, $p<.001)$ but not of Language $(p>.05)$. However, there was a significant Condition $\times$ Language interaction $(F 1(2,64)=4.46, \mathrm{MSE}=171.19, p<.05)$. This interaction effect indicates that the Stroop effect (incongruent-congruent) was significantly larger in the L1 $(43.3 \mathrm{~ms})$ compared to the L2 $(29.9 \mathrm{~ms} ; F 1(1,32)=$ 9.06, MSE $=327.4, p<.01$; Figure 5). This can be interpreted in terms of higher automaticity/activation of the first language.

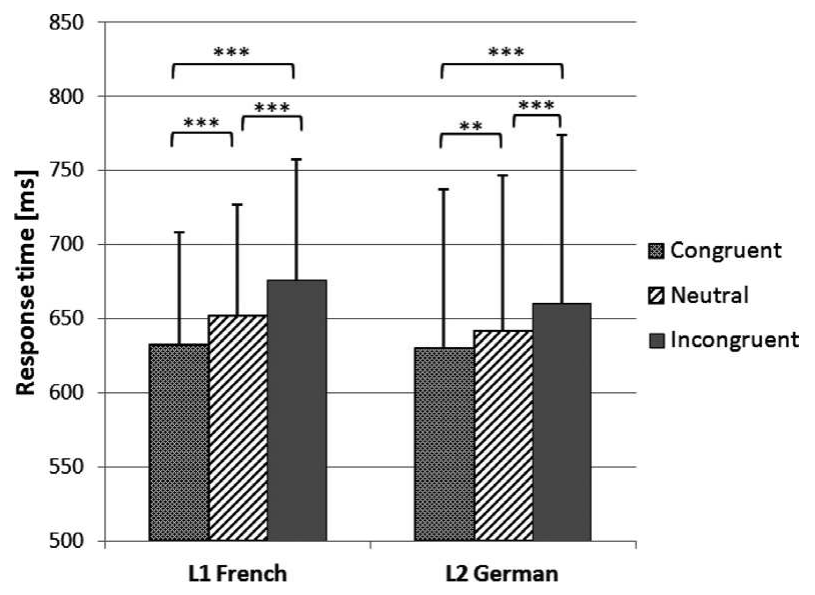

Figure 4. Mean response times (ms) and the standard deviations in the congruent, neutral and incongruent experimental conditions are plotted for bilinguals in their L1 and L2.

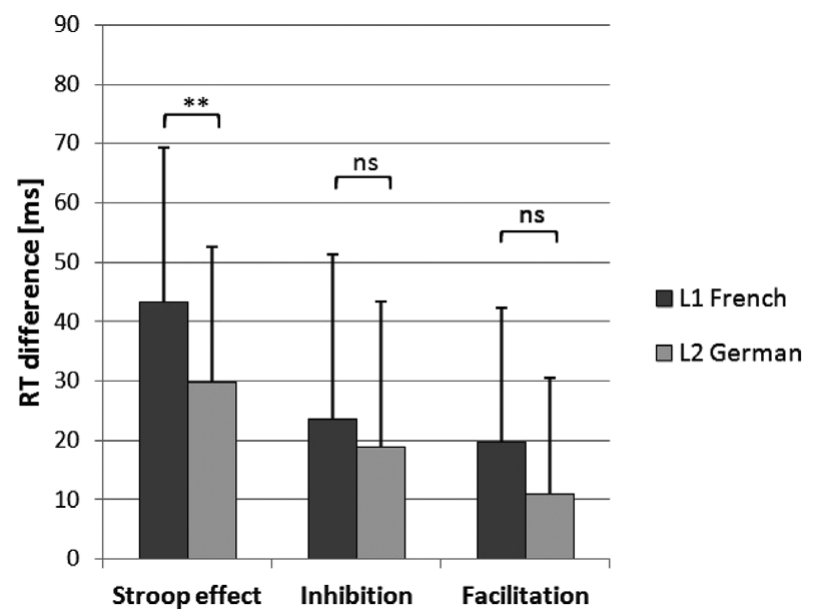

Figure 5. Mean Stroop Effect (ms) $\left(\mathrm{RT}_{\text {incongruent }}\right.$ $\mathrm{RT}_{\text {congruent }}$; Response time difference between the incongruent and the congruent condition), Inhibition effect $\left(\mathrm{RT}_{\text {incongruent }}-\mathrm{RT}_{\text {neutral }}\right)$ and Facilitation effect $\left(\mathrm{RT}_{\text {neutral }}-\right.$ $\mathrm{RT}_{\text {congruent }}$ ) with their respective standard deviations are indicated for L1 and L2 of bilinguals.

\section{The impact of different linguistic factors on the Stroop and Inhibition effects in L1 (French)}

A multiple regression analysis was conducted in order to determine which among the five linguistic factors we selected (i.e. frequency of L2 use, frequency of L3 use, L2 proficiency, duration of immersion in the L2 environment, and age of immersion) best account for the variance of the size of the Stroop effect (incongruent-congruent) in the L1 of the bilinguals. The results of the regression analysis indicated that the five predictors explained $27.1 \%$ of the variance of the Stroop effect size (Adjusted $\mathrm{R}^{2}=.271$, $F(5,32)=3.377, p<.05$, Cohen's $f^{2}=.37$; see Table 4$)$. The Cohen's $f^{2}$ of .37 indicates that this effect is in fact quite large. It was found that two variables significantly 
Table 4. Multiple regression analysis of L1 Stroop effect ( $\left.R T_{\text {incongruent }}-R T_{\text {congruent }}\right)$ size in bilinguals with frequency of L2 use, frequency of L3 use, L2 proficiency, duration of immersion in an L2 environment and age of immersion as predictor variables.

\begin{tabular}{lcrl}
\hline \hline & \multicolumn{2}{c}{$\mathrm{R}^{2}$ increments } \\
Predictors & $($ Coefficient $\beta)$ & $p$ \\
\hline Constant & 103.583 & 2.255 & .032 \\
Frequency of L2 use (\%) & -.171 & -0.922 & .365 \\
Frequency of L3 use (\%) & -.371 & -2.147 & .041 \\
L2 proficiency (\%) & -.282 & -1.696 .101 \\
Duration of immersion (years) & .587 & 3.325 & .003 \\
Age of immersion (years) & .080 & 0.464 .647 \\
\hline \hline
\end{tabular}

predicted the L1 Stroop effect size: the frequency of L3 use was negatively related to L1 Stroop effect size $(\beta=$ $-.371, p<.05$ ), while the duration of the immersion in the L2 environment was positively related to L1 Stroop effect size $(\beta=.587, p<.01)$. In contrast, for the L1 Inhibition effect (incongruent minus neutral), the model of multiple regression using the same predictors found none of the factors to be significant $(F<1)$.

\section{The impact of different linguistic factors on the Stroop and Inhibition effects in L2 (German)}

A multiple regression analysis was also conducted in order to predict the size of the L2 Stroop effect (incongruentcongruent) from the following factors: frequency of L2 use, frequency of L3 use, L2 proficiency, duration of immersion in an L2 environment, and age of immersion. The results of the regression indicated that the five predictors explained $26.5 \%$ of the variance of Stroop effect size (Adjusted $\mathrm{R}^{2}=.265, F(5,32)=3.311$, $p<.05$, Cohen's $f^{2}=.36$ ). The Cohen's $f^{2}$ of .36 indicates that this effect is also quite large. The duration of immersion in the L2 context was found to be positively related to the L2 Stroop effect size $(\beta=.631, p$ $<$.001; Table 5). In contrast, for the L2 Inhibition effect (incongruent minus neutral), the model of multiple regression using the same predictors found none of the factors to be significant $(F<1)$.

\section{Discussion}

\section{Bilingual advantage on inhibitory control}

In the present study, we examined the extent to which second language use impacts cognitive control. Our starting point was the hypothesis that the frequency of the L2 language use in successive bilingual individuals has an effect on their inhibitory control. To study
Table 5. Multiple regression analysis of L2 Stroop effect ( $\left.R T_{\text {incongruent }}-R T_{\text {congruent }}\right)$ size with frequency of $L 2$ use, frequency of L3 use, L2 proficiency, duration of immersion in an L2 environment and age of immersion as predictor variables.

\begin{tabular}{lcrl}
\hline \hline & \multicolumn{2}{c}{$\mathrm{R}^{2}$ increments } & \\
Predictors & $($ Coefficient $\beta)$ & $t$ & \multicolumn{1}{c}{$p$} \\
\hline Constant & -12.867 & -0.319 .752 \\
Frequency of L2 use (\%) & -.234 & -1.258 .219 \\
Frequency of L3 use (\%) & .083 & 0.481 .634 \\
L2 proficiency (\%) & .122 & 0.732 .470 \\
Duration of immersion (years) & .631 & 3.566 .001 \\
Age of immersion (years) & .079 & 0.459 .650 \\
\hline \hline
\end{tabular}

the factor frequency of L2 use, we tested bilingual participants from two linguistic environments. Cognitive control was studied while successive French-German bilinguals living either in French or German linguistic environments performed a Stroop task on both French and German words. Moreover, an additional control group constituted of monolingual native French speakers who lived in France was tested. Our results provide a clear-cut picture: the current immersion in a second language environment, i.e. an environment with high frequency of L2 use, is not a sufficient condition for improving the efficiency of the inhibition mechanism, as our ANOVA failed to show a modulation neither of the Stroop effect (incongruent-congruent) nor of the Inhibition effect (incongruent-neutral) as a function of the linguistic environment. Multiple regression analyses indicated that the use of multiple languages did play a central role for training inhibition, not, contrary to our expectations, by the frequency of the L2 use, but surprisingly, by the frequency of the L3 use, instead. In addition, the duration of immersion in an $\mathrm{L} 2$ environment was also a determining factor for explaining the efficiency of the inhibitory control, as it was found to be positively related to the L2 Stroop effect size.

The frequency of the L3 language use was negatively correlated to the L1 Stroop effect (incongruentcongruent) size. The more the bilinguals used an additional third language, the smaller their Stroop effect was. This result indicates that bilinguals who are highly trained to control a third language on a daily basis are less disturbed by interferences between reading and colour naming in the incongruent condition of a Stroop task. This finding suggests that the frequency of daily language use might be a determining factor to account for the better capacities of bilingual individuals to inhibit inappropriate/distracting information in tasks involving the resolution of conflicts. Our data reinforce the idea proposed by J. Diamond 
(2010) that additional language use beyond bilingualism might even increase a benefit on executive functions. Nevertheless, an alternative interpretation might be that additional language use of an L3 further decreases the respective language activation due to the reduction of the frequency of use of each language (Gollan, Montoya, Fennema-Notestine \& Morris, 2005); consequently the Stroop effect could decrease due to reduced interference.

However, given the absence of correlations between L1 and L3 $(p>.10)$ as well as between L2 and L3 $(p>.10)$ frequency of use, we can reasonably reject an interpretation in terms of decrease of language activation. Rather, our data suggest that the relation between L3 frequency of use and L1 Stroop effect size that we report here might be better explained in terms of an enhancement of inhibitory control due to the regular use of several languages.

Moreover, the observation in the present study that the duration of the immersion positively correlated with the Stroop effect in both languages constitutes an argument in favour of a model postulating increased inhibitory control rather than decreased language activation. It is likely that at the beginning of the immersion in an L2 environment, there is a huge challenge to control the language use as the control over languages is plausibly not yet automatized, and, therefore might require strong top-down inhibitory control. As the duration of immersion increases, the control processes may at least partially become automatized and top-down control gets less implicated. For this reason, in our study, maximal bilingual advantage was found in the case of short rather than long durations of immersion. Nevertheless, although the Stroop effect varies as a function of the duration of the immersion, it remains smaller than it does for monolinguals.

In addition to the positive correlation between the Stroop effect size and the duration of the immersion observed for both languages of the bilinguals (L1 and L2) the Stroop effects in the two languages were positively correlated $(\beta=.460, p<.01)$. On the basis of this observation, the following rationale for attempting to separate between an inhibition and an activation account explaining the bilingual advantage is proposed: Language activation is supposed to vary with respect to language dominance, which is to a large degree dependent on the frequency of the use of each language as well as on the duration of the immersion in the respective language environment. If the Stroop effect size mainly depends on the language activation, the correlation between the Stroop effects in the two languages should be negative: increased activation of one language due to its frequent use should be accompanied with a reduced activation of the other language. In the present study, we found the reverse result (positive correlation) suggesting that bilingualism advantage could be explained by the differences in the inhibitory control.

Moreover, we were able to replicate the advantage of bilingualism both for the Stroop effect (incongruentcongruent) and for the Inhibition effect (incongruentneutral) as already found in previous studies (BadzakovaTrajkov, 2008; Bialystok, 2006; Bialystok \& DePape, 2009; Costa et al., 2008). This reinforces the idea that activities such as multiple language use are most likely to cause an improvement of the executive functions, even if young adults already have a high capacity (A. Diamond, 2006, 2011). Overall, the bilingual participants performed the Stroop task better than the monolingual individuals. This was mainly due to the fact that bilinguals were less disturbed in the incongruent condition in comparison with the monolinguals as indicated by the significantly smaller Inhibition effect for the bilinguals (i.e. $23.6 \mathrm{~ms}$ ) than for the monolinguals (i.e. $42.2 \mathrm{~ms}$ ). Taken together, these results converge to show that in comparison with monolinguals bilinguals have better inhibitory control as they are more efficient in order to suppress distracting information when this information competes with the information needed to perform a cognitive task.

The absence of variation of the size of the Stroop effect in the course of the experiment suggests that the Stroop effect size does not depend on short-term practice of a Stroop task. In contrast, given the advantageous effect of bilingualism the Stroop effect size appears to be modulated by long-term training.

\section{Effect of Language on the Stroop effect}

A further hypothesis tested in the present study was that the interference of the automatic process of reading on the (more) controlled process of print colour naming should be stronger in L1 than in L2 due to the higher automaticity of L1 compared to L2. Therefore, we predicted a larger Stroop effect (incongruent-congruent) in L1 than in L2. Our data confirmed this prediction: A larger Stroop effect was found in the L1 as opposed to the L2. This finding can be interpreted within the framework of the temporal delay assumption, as derived from the BIA + model (Dijkstra \& Van Heuven, 2002), i.e. that the access to phonological and semantic codes is assumed to be delayed in the L2 in comparison to the L1. Under this assumption, the L2 takes more time to be activated than the L1 in bilinguals. Due to slower lexical access in the L2, L2 words should interfere less in the Stroop task. Interestingly, the L1 remained the dominant language in the bilingual individuals we tested in the German linguistic environment as suggested by the larger effect in the L1 than in the L2. Note, however, that a change of language dominance has been shown to occur after a longer stay in the L2 environment. Indeed, Bahrick, Hall, Goggin, Bahrick and Berger (1994), using different grammatical and vocabulary tests, found a change of 
dominance in favour of L2 for a stay in the L 2 environment around 12 years. Attrition of L1, that is language loss, can be one of the consequences of longer stays in an L2 environment (Köpke, 2004, for a review; Schmid \& Köpke, 2007).

\section{Models on bilingual language processing}

In the present section, we will attempt to discuss which of the two models of bilingual language processing (i.e. Inhibitory Control and Bilingual Interactive Activation models) can better account for the empirical data we have presented here.

The INHIBITORY CONTROL (IC) model (Green, 1998) postulates a higher-order level of attentional control being exerted both on linguistic and non-linguistic domains. In the IC model, this higher-order level of control is called the Supervisory Attentional System (SAS). The SAS is assumed to regulate the activation of lexical and phonological units. The justification of such a top-down inhibitory control in language selection relies on the assumption that first and second languages (and further languages for multilingual individuals) are initially coactivated (Brysbaert, 2003; Dijkstra, 2005). Consequently, this language co-activation requires top-down inhibitory control in order to avoid inter-lingual interferences. The language control process is executed via multiple levels of control. Activation of each language is regulated via language TAGS by their respective "language task schemas", which are themselves controlled by the SAS. If the assumption that the SAS constitutes a general inhibitory control exerted on language selection in a multilingual environment is valid, then multiple language use may function as training to this control mechanism. Bilinguals may thus have an advantage over monolinguals in top-down inhibitory control. Furthermore, inhibitory control is expected to be more efficient in suppressing a less dominant language than a more dominant language in bilingual language use.

An alternative psycholinguistic model on bilingual language control is the BILINGUAL InTERACTIVE ACtivation+ $(\mathrm{BIA}+)$ model (Dijkstra \& Van Heuven, 2002; Van Heuven et al., 1998). Like the IC model (Green, 1998), the BIA+ model postulates an initial coactivation of both languages in bilingual individuals. In the BIA+ model, all levels of inhibitory control on language selection and inhibition are specific to the language domain. Words of the non-target language are inhibited by so-called "language nodes". Therefore, a crucial difference between the IC model and the BIA+ model lies in the localisation of the levels of control on language selection and inhibition. Whereas the IC model relies on the assumption of an active top-down inhibition, the BIA+ postulates an automatic inhibition, i.e. a lateral inhibition between language nodes. In this mechanism, as one language node accumulates more evidence, the node inhibits the lexical representations associated with the other language nodes; until, finally, the winner takes all. Thus, language selection in the BIA+ mainly relies on differences between activation levels of L1 and L2. Dijkstra and Van Heuven (2002) point out that, in bilingual language use, the L2 is generally activated to a lower level than the L1 (see temporal delay assumption). The difference in resting activation of the L1 and L2 is supposed to be due to differences in frequency of use as well as to language dominance. ${ }^{4}$ Finally, following the assumption of a higher-order level of control being exerted both on linguistic and non-linguistic domains, the IC model can account for bilingual advantages either in tasks involving a linguistic component (e.g. Stroop task) or not (e.g. Simon task); in contrast, the BIA+ can only account for advantages in tasks involving a linguistic component.

Akin to the assumption of a temporal delay of lexical access in L2 for bilinguals made in the BIA+ model, Gollan et al. (2005) proposed that each of a bilingual's languages, including even their L1, is less activated at rest, and thus has weaker links to the conceptual level, than in monolingual language use. Likewise, Ivanova and Costa (2008) and Pyers, Gollan and Emmorey (2009) claimed that bilinguals' disadvantages in lexical access in their L1 compared to monolinguals may be due to the reduced frequency of use devoted to each single language. Deducing from these hypotheses on frequency-dependent differences, a potential advantage of bilingualism in a task requiring the inhibition of linguistic information - like the Stroop task - may primarily be caused by the lower activation of each of the bilinguals' languages. Top-down inhibition may therefore be more efficient on the lower activated L1 in bilinguals in comparison to monolinguals.

In our study, the observation of a bilingual advantage for performing tasks involving inhibitory control could be explained either by an inhibition theory (i.e. inhibit interference of the automatic process of reading on the more controlled process of colour naming) or by an activation theory (i.e. lower activation level of the L1 that would explain the reduced interference of reading on naming). However, given the assumption that bilingual or multilingual language use involves inhibition of the non-target language(s), the observation that the size of the Stroop effect in bilinguals was modulated by the frequency of the use of a foreign language, here the L3 not the hypothesized L2, reinforces the idea that inhibitory control rather than reduced language activation can account for the bilingual advantage found in the present study. Moreover, we showed that the reduced

\footnotetext{
4 A multifaceted characterization of the role of each language for a multilingual person, including e.g. speed of lexical access, size of the vocabulary, written and oral comprehension (Bahrick et al., 1994; Meisel, 2007).
} 
Stroop effect observed in bilinguals was due to a smaller Inhibition effect (incongruent minus neutral condition) in bilingual than in monolingual individuals, a further argument in favour of stronger inhibition in bilinguals than in monolinguals. However, whether the smaller interference effect observed in the incongruent condition for bilingual as compared to monolingual individuals was due to more efficient inhibition and/or a different activation level for L1 depending on the use of a second language remains an open question. Further investigation is needed into the functional architecture of the models of bilingual language processing. Altogether, the data from the present study are compatible with both inhibition and facilitation models. Therefore, we hypothesize that a hybrid functional architecture may give a better account for such data. Consequently, an experimental design that helps to distinguish between inhibitory and activation mechanisms, is needed in future research on this type of model of bilingualism. In order to disentangle the respective contribution of trained executive functions and language activation, future research should investigate executive functions using tests assumed to largely exclude the involvement of linguistic aspects (i.e. the Simon or Tower of Hanoi tasks). Such tests would allow us to isolate inhibitory control.

\section{Conclusion}

We hypothesized that frequency of L2 use, depending on linguistic environment, would have an effect on inhibitory control. We found that the use of multiple languages did play a central role for training inhibition. However, contrary to our expectations, inhibitory control was influenced not by the frequency of L2 use but, surprisingly, by the frequency of L3 use. Additionally, we showed that the duration of the immersion in an L2 environment is also a relevant predictor of inhibitory control. Furthermore, we were able to replicate a bilingual advantage employing a Stroop Colour Word task (usually used to test inhibitory control among the executive functions). Taken together, our data highlighted that those bilinguals with an additional third language appear to have a higher capacity for inhibiting interferences in cases of conflicts between competing information. Concretely, bilinguals with highly trained control mechanism seem to be able to suppress distracting information better when this information competes with the information needed to perform a cognitive task. Therefore, the present findings reinforce the idea that there is a general level of cognitive control involved in the control of multiple language use and consequently, that the capacity for inhibitory control can be improved by the use of more than one language. Further investigation with trilingual participants should be conducted in order to examine the inhibition processes in the case of multiple inter-lingual competitions. Finally, to decide between inhibition and facilitatory theories in psychology, and, in particular, to study the cognitive inhibition in a direct manner, future investigations in cognitive neuroscience should find a way to examine mechanisms of cognitive inhibition at a neurophysiological level. For this purpose, it would be relevant to perform measures of the activity of Gamma-aminobutyric acid (GABA) neurons (i.e. neurons inducing inhibition of target neurons) between brain regions assumed to support the control of other regions by turning them down. Furthermore, neuroimaging methods such as functional magnetic resonance imaging (fMRI) will help us validate inhibition models in psychology by determining which neuronal circuit supports cognitive inhibition (for the increasing number of studies examining the neural bases cognitive control in bilingual language use, see, e.g. Abutalebi, Della Rosa, Green, Hernandez, Scifo, Keim, Cappa \& Costa, 2012; Garbin, Sanjuan, Forn, Bustamante, Rodriguez-Pujadas, Belloch, Hernandez, Costa \& Ávila, 2010; Luk, Anderson, Craik, Grady \& Bialystok, 2010; Luk, Bialystok, Craik \& Grady, 2011; for reviews, see Abutalebi \& Green, 2008; Luk, Green, Abutalebi \& Grady, 2012). Recently, it has been argued that a fronto-subthalamic circuit, or some part thereof (e.g. inferior frontal cortices and subthalamic nucleus) could be recruited across a wide range of control mechanisms. Whether this circuit is also recruited for cognitive control remains to be studied in further cognitive neuroscientific research.

\section{References}

Abutalebi, J., Della Rosa, P. A., Green, D. W., Hernandez, M., Scifo, P., Keim, R., Cappa, S. F., \& Costa, A. (2012). Bilingualism tunes the anterior cingulate cortex for conflict monitoring. Cerebral Cortex, 22, 2076-2086.

Abutalebi, J., \& Green, D. W. (2008). Control mechanisms in bilingual language production: Neural evidence from language switching studies. Language and Cognitive Processes, 23, 557-582.

Aron, A. R. (2007). The neural basis of inhibition in cognitive control. The Neuroscientist, 13, 214-228.

Badzakova-Trajkov, G. (2008). A behavioural and functional imaging investigation of Stroop task performance in late proficient bilinguals. Ph.D. thesis, The University of Auckland.

Badzakova-Trajkov, G., Barnett, K. J., Waldie, K. E., \& Kirk, I. J. (2009). An ERP investigation of the Stroop task: The role of the cingulate in attentional allocation and conflict resolution. Brain Research, 1253, 139-148.

Bahrick, H. P., Hall, L. K., Goggin, J. P., Bahrick, L. E., \& Berger, S. A. (1994). Fifty years of language maintenance and language dominance in bilingual Hispanic immigrants. Journal of Experimental Psychology: General, 123, 264 283. 
Best, J. R., \& Miller, P. H. (2010). A developmental perspective on executive function. Child Development, 81, 1641-1660.

Bialystok, E. (2001). Bilingualism in development: Language, literacy, and cognition. New York: Cambridge University Press.

Bialystok, E. (2005). Consequences of bilingualism on cognitive development. In Kroll \& De Groot (eds.), pp. 417-432.

Bialystok, E. (2006). Effect of bilingualism and computer video game experience on the Simon task. Canadian Journal of Experimental Psychology, 60, 68-79.

Bialystok, E. (2007). Cognitive effects of bilingualism: How linguistic experience leads to cognitive change. International Journal of Bilingual Education and Bilingualism, 10, 210-223.

Bialystok, E. (2010). Global-local and trail-making tasks by monolingual and bilingual children: Beyond inhibition. Developmental Psychology, 46, 93-105. doi: $10.1037 / \mathrm{a} 0015466$

Bialystok, E., Craik, F. I. M., Klein, R., \& Viswanathan, M. (2004). Bilingualism, aging, and cognitive control: Evidence from the Simon task. Psychology and Aging, 19, 290-303.

Bialystok, E., Craik, F. I. M., \& Luk, G. (2008). Cognitive control and lexical access in younger and older bilinguals. Journal of Experimental Psychology: Learning, Memory, and Cognition, 34, 859-873.

Bialystok, E., Craik, F. I. M., \& Ryan, J. (2006). Executive control in a modified Antisaccade task: Effects of aging and bilingualism. Journal of Experimental Psychology: Learning, Memory, and Cognition, 32, 1341-1354.

Bialystok, E., \& DePape, A.-M. (2009). Musical expertise, bilingualism, and executive functioning. Journal of Experimental Psychology: Human Perception and Performance, 35, 565-574.

Bialystok, E., \& Martin, M. M. (2004). Attention and inhibition in bilingual children: Evidence from the dimensional change card sort task. Developmental Science, 7, 325-339.

Bjorklund, D. F., \& Harnishfeger, K. K., (1995). The evolution of inhibition mechanisms and their role in human cognition and behavior. In F. N. Dempster \& C. J. Brainerd (eds.), Interference and inhibition in cognition, pp. 141-173. San Diego, CA: Academic Press.

Blais, C., \& Bunge, S. (2010). Behavioral and neural evidence for item-specific performance monitoring. Journal of Cognitive Neuroscience, 22, 2758-2767.

Bruchmann, M., Herper, K., Konrad, C., Pantev, C., \& Huster, R. J. (2010). Individualized EEG source reconstruction of Stroop interference with masked color words. NeuroImage, 49, 1800-1809.

Brysbaert, M. (2003). Bilingual visual word recognition: Evidence from masked phonological priming. In $\mathrm{S}$. Kinoshita \& S. J. Lupker (eds.), Masked priming: Stateof-the-art. Hove: Psychology Press.

Bugg, J. M. (2012). Dissociating levels of cognitive control: The case of Stroop Interference. Current Directions in Psychological Science, 21, 302-309.

Carlson, S. M., \& Meltzoff, A. M. (2008). Bilingual experience and executive functioning in young children. Developmental Science, 11, 282-298.
Chertkow, H., Whitehead, V., Phillips, N., Wolfson, C., Atherton, J., \& Bergman, H. (2010). Multilingualism (but not always bilingualism) delays the onset of Alzheimer's disease evidence from a bilingual community. Alzheimer's Disease \& Associated Disorders, 24, 118-125.

Coderre, E., Conklin, K., \& Van Heuven, W. J. B. (2011). Electrophysiological measures of conflict detection and resolution in the Stroop task. Brain Research, 1413, 5159.

Costa, A., Hernández, M., Costa-Faidella, J., \& Sebastián-Gallés, N. (2009). On the bilingual advantage in conflict processing: Now you see it, now you don't. Cognition, 113, 135-149.

Costa, A., Hernández, M., \& Sebastián-Gallés, N. (2008). Bilingualism aids conflict resolution: Evidence from the ANT task. Cognition, 106, 59-86.

De Neys, W., \& Van Gelder, E. (2009). Logic and belief across the lifespan: The rise and fall of belief inhibition during syllogistic reasoning. Developmental Science, 12, 123-130.

Diamond, A. (2006). The early development of executive functions. In E. Bialystok \& F. I. M. Craik (eds.), Lifespan cognition: Mechanisms of change, pp. 70-95. New York: Oxford University Press

Diamond, A. (2011). Biological and social influences on cognitive control processes dependent on prefrontal cortex. In O. Braddick, J. Atkinson \& G. M. Innocenti (eds.), Progress in Brain Research (vol. 189), pp. 319-339. Burlington: Academic Press.

Diamond, A., \& Lee, K. (2011). Interventions shown to aid executive function development in children 4 to 12 years old. Science, 333, 959-964.

Diamond, J. (2010). The benefits of multilingualism. Science, $330,332-333$

Dijkstra, T. (2005). Bilingual visual word recognition and lexical access. In Kroll \& De Groot (eds.), pp. 179-201.

Dijkstra, T., \& Van Heuven, W. J. B. (2002). The architecture of the bilingual word recognition system: From identification to decision. Bilingualism: Language and Cognition, 5, 175197.

Garbin, G., Sanjuan, A., Forn, C., Bustamante, J. C., Rodriguez-Pujadas, A., Belloch, V., Hernandez, M., Costa, A., \& Ávila, C. (2010). Bridging language and attention: Brain basis of the impact of bilingualism on cognitive control. NeuroImage, 53, 1272-1278.

Gathercole, V. C. M., Thomas, E. M., Jones, L., Guasch, N. V., Young, N., \& Hughes, E. K. (2010). Cognitive effects of bilingualism: Digging deeper for the contributions of language dominance, linguistic knowledge, socioeconomic status and cognitive abilities. International Journal of Bilingual Education and Bilingualism, 13, 617664.

Godefroy, O., Jeannerod, M., Allain, P., \& Le Gall, D. (2008). Lobe frontal, fonctions exécutives et controle cognitif: Frontal lobe, executive functions and cognitive control. Revue Neurologique, 164, 119-127.

Gollan, T. H., Montoya, R. I., Fennema-Notestine, C., \& Morris, S. K. (2005). Bilingualism affects picture naming but not picture classification. Memory and Cognition, 33, 1220 1234 
Green, D. W. (1998). Mental control of the bilingual lexicosemantic system. Bilingualism: Language and Cognition, 1, 67-81.

Hanslmayr, S., Pastötter, B., Bäuml, K.-H., Gruber, S., Wimber, M., \& Klimesch, W. (2008). The electrophysiological dynamics of interference during the Stroop task. Journal of Cognitive Neuroscience, 20, 215-225.

Isel, F., Baumgaertner, A., Thrän, J., Meisel, J. M., \& Büchel, C. (2010). Neural circuitry of the bilingual mental lexicon. Effect of age of second language acquisition. Brain and Cognition, 72, 169-180.

Ivanova, I., \& Costa, A. (2008). Does bilingualism hamper lexical access in speech production? Acta Psychologica, 127, 277-288.

Köpke, B. (2004). Neurolinguistic aspects of attrition. Journal of Neurolinguistics, 17, 3-30.

Kousaie, S., \& Phillips, N. A. (2012). Ageing and bilingualism: Absence of a "bilingual advantage" in Stroop interference in a nonimmigrant sample. The Quarterly Journal of Experimental Psychology, 65, 356-369.

Kovács, A. M. (2009). Early bilingualism enhances mechanisms of false-belief reasoning. Developmental Science, 12, 4854.

Kovács, A. M., \& Mehler, J. (2009). Cognitive gains in 7-monthold bilingual infants. Proceedings of the National Academy of Sciences, 106, 6556-6560.

Kroll, J. F., Bogulski, C. A., \& McClain, R. (2012). Psycholinguistic perspectives on second language learning and bilingualism: The course and consequence of cross-language competition. Linguistic Approaches to Bilingualism, 2, 1-24.

Kroll, J. F., \& De Groot, A. M. B. (eds.) (2005). Handbook of bilingualism: Psycholinguistic approaches. New York: Oxford University Press.

Kroll, J. F., Dussias, P. E., Bogulski, C. A., \& Valdes Kroff, J. R. (2012). Juggling two languages in one mind: What bilinguals tell us about language processing and its consequences for cognition. Psychology of Learning and Motivation, 56, 229-262.

Linck, J. A., Hoshino, N., \& Kroll, J. F. (2008). Crosslanguage lexical processes and inhibitory control. The Mental Lexicon, 3, 349-374.

Linck, J. A., Kroll, J. F., \& Sunderman, G. (2009). Losing access to the native language while immersed in a second language. Psychological Science, 20, 1507-1515.

Liotti, M., Woldorff, M. G., Perez III, R., \& Mayberg, H. S. (2000). An ERP study of the temporal course of the Stroop color-word interference effect. Neuropsychologia, 38, 701711.

Luk, G., Anderson, J. A. E., Craik, F. I. M., Grady, C. L., \& Bialystok, E. (2010). Distinct neural correlates for two types of inhibition in bilinguals: Response inhibition versus interference suppression. Brain and Cognition, 74, 347357.

Luk, G., Bialystok, E., Craik, F. I. M., \& Grady, C. L. (2011). Lifelong bilingualism maintains white matter integrity in older adults. Journal of Neuroscience, 31, 16808-16813.

Luk, G., de Sa, E., \& Bialystok, E. (2011). Is there a relation between onset age of bilingualism and enhancement of cognitive control? Bilingualism: Language and Cognition, 14, 588-595.

Luk, G., Green, D. W., Abutalebi, J., \& Grady, C. L. (2012). Cognitive control for language switching in bilinguals: A quantitative meta-analysis of functional neuroimaging studies. Language and Cognitive Processes, 27, 14791488.

MacLeod, C. M., \& MacDonald, P. A. (2000). Interdimensional interference in the Stroop effect: Uncovering the cognitive and neural anatomy of attention. Trends in Cognitive Sciences, 4, 383-391.

MacWhinney, B. (2005). A unified model of language acquisition. In Kroll \& De Groot (eds.), pp. 49-67.

Meisel, J. M. (2007). The weaker language in early child bilingualism: Acquiring a first language as a second language. Applied Psycholinguistics, 28, 495-514.

Misra, M., Guo, T., Bobb, S. C., \& Kroll, J. F. (2012). When bilinguals choose a single word to speak: Electrophysiological evidence for inhibition of the native language. Journal of Memory and Language, 67, 224237.

Miyake, A., Friedman, N. P., Emerson, M. J., Witzki, A. H., Howerter, A., \& Wager, T. D. (2000). The unity and diversity of executive functions and their contributions to complex "Frontal Lobe" tasks: A latent variable analysis. Cognitive Psychology, 41, 49-100.

Morton, J. B., \& Harper, S. N. (2007). What did Simon say? Revisiting the bilingual advantage. Developmental Science, 10, 719-726.

Naylor, L. J., Stanley, E. M., \& Wicha, N. Y. Y. (2012). Cognitive and electrophysiological correlates of the bilingual Stroop effect. Frontiers in Psychology, 3. doi:10.3389/fpsyg.2012.00081.

Nowagk, R. (1998). Conan: A Barbarian Tool for Constrained Randomization (Version 1.9). Leipzig: Max-PlanckInstitute of Cognitive Neuroscience Leipzig.

Pardo, J. V., Pardo, P. J., Janer, K. W., \& Raichle, M. E. (1990). The anterior cingulate cortex mediates processing selection in the Stroop attentional conflict paradigm. Proceedings of the National Academy of Sciences, 87, 256-259.

Prior, A., \& MacWhinney, B. (2010). A bilingual advantage in task switching. Bilingualism: Language and Cognition, 13, 253-262.

Pyers, J. E., Gollan, T. H., \& Emmorey, K. (2009). Bimodal bilinguals reveal the source of tip-of-the-tongue states. Cognition, 112, 323-329.

Qiu, J., Luo, Y., Wang, Q., Zhang, F., \& Zhang, Q. (2006). Brain mechanism of Stroop interference effect in Chinese characters. Brain Research, 1072, 186-193.

Schmid, M. S., \& Köpke, B. (2007). Bilingualism and attrition. In B. Köpke, M. S. Schmid, M. Keijzer \& S. Dostert, (eds.), Language attrition: Theoretical perspectives, pp. 1-7. Amsterdam \& Philadelphia, PA: John Benjamins.

Simon, J. R., \& Ruddell, A. P. (1967). Auditory S-R compatibility: The effect of an irrelevant cue on information processing. Journal of Applied Psychology, 51, 300-304.

Stroop, J. R. (1935). Studies of interference in serial verbal reactions. Journal of Experimental Psychology, 18, 643- 
662; reprint (1992): Journal of Experimental Psychology: General, 121, 15-23.

Tao, L., Marzecová, A., Taft, M., Asanowicz, D., \& Wodniecka, Z. (2011). The efficiency of attentional networks in early and late bilinguals: The role of age of acquisition. Frontiers in Psychology, 2. doi: 10.3389/fpsyg.2011.00123.

Tokowicz, N., \& MacWhinney, B. (2005). Implicit and explicit measures of sensitivity to violations in second language grammar - an event-related potential investigation. Studies in Second Language Acquisition, 27, 173-204.

Treitz, F. H. (2006). Die Veränderungen der Exekutivfunktionen während des nicht-pathologischen Alterungsprozesses: Verlauf und Prädiktoren. Ph.D. thesis, Ruhr-Universität Bochum.
Van Heuven, W. J. B., Dijkstra, T., \& Grainger, J. (1998). Orthographic neighbourhood effects in bilingual word recognition. Journal of Memory and Language, 39, 458483.

Van Veen, V., \& Carter, C. S. (2005). Separating semantic conflict and response conflict in the Stroop task: A functional MRI study. Neuroimage, 27, 497-504.

Yang, S., Yang, H., \& Lust, B. (2011). Early childhood bilingualism leads to advances in executive attention: Dissociating culture and language. Bilingualism: Language and Cognition, 14, 412-422.

Zelazo, P. D., Craik, F. I. M., \& Booth, L. (2004). Executive function across the life span. Acta Psychologica, 115, 167184. 